\title{
Comparative Study of Intestinal Parasitic Infection among Pregnant and Non-Pregnant Women in Owerri, Nigeria: A Case Study of the Federal Medical Centre, Owerri
}

\begin{abstract}
'Department of Histopathology, Federal Medical Center (FMC), Owerri, Imo State, Nigeria.
${ }^{2}$ Department of Medical Parasitology, School of Medical Laboratory Sciences, University of Port-Harcourt
Abstract

A survey of intestinal parasites of pregnant and non-pregnant women attending the Federal Medical Centre, Owerri, Imo State, Nigeria was carried out between November 2010 and April 2011. A total of 300 samples (150 from pregnant women and 150 from non - pregnant women respectively) were randomly collected from these women who attended the hospital. The samples were examined using the direct wet preparation and formol ether concentration technique. A total of $41(13.67 \%)$ women were infected. The infected stool samples contained eggs of Ascaris lumbricoides (48.78\%), Hookworm (39.02\%), and Cysts of Entamoeba histolytica $(12.20 \%)$. Although, more pregnant women $(16(39.02 \%)$ ), the difference was not statistically significant. The highest prevalence of $20 \%$ was observed in the pregnant women within the age - group of 27-30 while the age group of 19-22 years. The difference between the prevalence of infection in the age group was significant. However personal hygiene improved health education programs and supervised public toilets together with food vendor's education have been recommended as measures to eradicate intestinal parasitic infections among pregnant and non-pregnant women. It has been recommended that stool analysis should be part of the antenatal screening tests particularly in subjects with a high level of parasitemia.
\end{abstract}

Olaleye W. Babatunde ${ }^{1,2, *}$, Awah, I.J. ${ }^{2}$, Abosede A. Babatunde ${ }^{1}$ Teaching Hospital, Port-Harcourt, Rivers State, Nigeria.

*Corresponding author email: babos077@yahoo.com; Phone: +2348035348508
Keywords: Parasitic Infection, Ascaris lumbricoides, Hookworm, Entamoeba histolytica
Article History
Received: 6 Dec 2021

Accepted: 21 Dec 2021

Published: 05 Jan 2022

Scan QR code to view

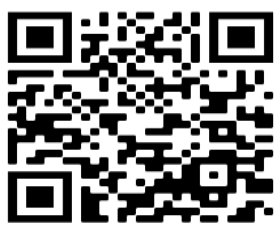

License: CC BY 4.0

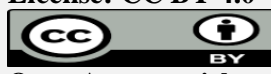

Open Access article.

How to cite this paper: Babatunde, O.W., Awah, I.J., Babatunde, A.A. (2022). Comparative Study of Intestinal Parasitic Infection among Pregnant and Non Pregnant Women in Owerri, Nigeria: A Case Study of the Federal Medical Centre, Owerri. Scicom J Med Appl Med Sci, 1(1), 13-18. https://doi.org/10.54117/sjmams.v1i1.3

\section{Introduction}

Over the years, parasitic infections have been a problem in both the developing and the developed worlds. Though the published incidence rates vary for different localities, states, the type of patients surveyed, and the source of the surveyed materials, the extent of natural parasitic infections among Nigerians and other developing countries is not fully established [1-6]. Among parasitic infections, malaria and intestinal helminths coexist widely with micronutrient deficiencies and contribute importantly to anemia with a cycle of retarded growth and development [7]. Intestinal worm infections are common worldwide but thrive in poor communities in the tropic where poor water supply and poor sanitation are common. The poor growth resulting in underweight and stunting leaves reproductive-age women at risk in their early pregnancies of delivering premature or low birth weight infants. Infants born prematurely or with low birth weight are at increased risk of early death but are also at risk of poor growth and development in childhood and adolescence [7]. In addition, the micronutrient deficiencies particularly iron and folate deficiencies (which contribute to anemia) leaves the young women at risk of anemia leading to inadequate oxygen-carrying capacity and risk in pregnancy of delivering premature or low birth weight infants.
Studies carried out in Nigeria and other parts of the world have shown that protozoa and helminth parasites are the commonest intestinal parasites of man $[1,3,5]$. Protozoa and helminth parasites are endemic in many parts of Nigeria. The case of high prevalence has been attributed to the human, ecological, economic, and social factors that make transmission of parasites and susceptibility of host possible $[4,6,8]$. A large proportion of this work involves a logical examination of parasites in hospital patients or other specific groups within the community. To provide and promote the health of mothers and children constitute the overall objectives of the World Health Organization (WHO) program on maternal and child health. One out of two infants' death occurs during the firth month of life [9]. In Northern Nigeria, teenage mothers (below 17 years with no antenatal care) have a death rate of 50-70 per 1000 births [9]. Newborn mortality is related to the health of the mother both before and during pregnancy. This has led to an increasing interest in the health of pregnant women with a view of improving their condition through antenatal-based health programs.

Pregnancy demands maternal energy for the growing fetus, which requires nutrients such as fats, proteins, and carbohydrates for normal growth and development. Intestinal parasites are a common occurrence in pregnancy however, environmental, nutritional, and immunologic factors influence the clinical manifestations and determine the need for treatment 
of intestinal parasitism during pregnancy. Intestinal parasitic infections transmitted through the soil and water include ascariasis, amoebiasis, hookworm disease, etc. These infections cause intestinal symptoms coupled with having an adverse effect which may result in anemia, premature births, or infants with low birth weight [1]. These infants are especially vulnerable to loss of body weight leading to neo-natal death. It has been reported that iron deficiency anemia is commonly associated with hookworm infection [10]. Parasitic infections have been recognized as causing health problems in many parts of the world. In our rural communities, they pose health social, and economic problems which have far-reaching effects on the economy of the country, especially by reducing the productive labor force. It is rightly stated that "the development of a nation and its economy is tied to the health of the workforce".

Therefore, it is important to ensure that the working population of which women are part, is healthy at all times.

1. Investigate the prevalence of intestinal parasites among pregnant and non-pregnant women attending Federal Medical Centre, Owerri, Imo State.

2. Relate the infections to the demographic and environmental factors prevailing in their communities.

\section{Materials and Methods}

The survey was carried out within four months (November 2010 -April 2011 ) on 300 stool samples (150 from pregnant women and 150 from non-pregnant women) attending Federal Medical Centre, Owerri, Imo State.

\section{Method of Survey}

A questionnaire covering information such as name, age, occupation, and environmental factors were given to every subject to be interviewed (Appendix I).

\section{Collection of Samples}

Stool samples were collected from a total of three hundred women (150 from pregnant and 150 non-pregnant women) attending Federal Medical Centre, Owerri, Imo State. The stool samples from pregnant women will be collected from those attending their antenatal clinic while these samples from non-pregnant women will be from those coming for routine laboratory tests in the parasitology department in the hospital. Clean, dry, and leak-proof plastic universal bottles will be given to the women on their antenatal/laboratory days, some of them will produce the sample on the same day while others may go home with the bottles and return on their next visit to the hospital.

The direct smear method, using normal saline and iodine for wet mount preparation and concentration procedures using formol-ether technique for the identification of helminth eggs and protozoan cysts was adopted through macroscopic examination. See Appendix II for the preparation of reagents.

\section{Macroscopic Stool Examination}

Physical characteristics of the stool samples e.g color of the samples, consistency (i.e whether formed, semi-informed, uniformed, or watery), presence of blood, mucus, or pus, and whether the sample(s) contains adult worms will be examined.

\section{Direct Smear}

As described by Cheesbrough [11], this involves saline and iodine preparations. In saline preparation, a drop of fresh physiological saline was placed on one end of a clean grease-free slide and a drop of iodine on the other end using an application stick to apply a small amount (about $2 \mathrm{mg}$ ) of the sample (i.e match stick head amount); each was mixed with both the saline and iodine respectively until a smooth thin preparation is obtained. Each preparation was covered with the condenser iris closed sufficiently to give a good contrast. The iodine preparation was used to assist in the identification of cysts.

\section{Formol-ether Concentration Techniques}

This was carried out to sediment parasites by centrifugal force. Procedures [11].
1. Using an applicator stick, an estimated $1 \mathrm{~g}$ of the fecal sample taken from the surface and several places in the sample was emulsified in about $4 \mathrm{~m}$ of $10 \%$ formal saline contained in a screw-cap bottle.

2. A further $4 \mathrm{ml}$ of $10 \%$ formal saline was added, the bottle was capped and mixed by shaking for about 20 seconds.

3. The emulsified feces was sieved with the trainer and the sieved suspension was collected in a beaker.

4. The suspension was transferred to a glass test tube with a cap and an equal volume of diethyl-ether $(4 \mathrm{ml})$.

5. The test tube was capped and mixed for 1 minute

6. With a tissue wrapped around the top of the tube, the cap was loosened and the mixture was immediately centrifuged at approximately 3,000rpm for 1 minute. After centrifugation, the mixture was separated as shown in figure 1.

7. With the use of an applicator stick, the layer of the fecal debris was loosened from the side of the tube and the tube immediately inverted to discard the ether, fecal debris, and formal water and the sediment remained.

8. The tube was returned to its upright position and the fluid from the side of the tube was allowed to drain to the bottom of the tube.

9. The bottom of the tube was tapped to resuspend and mix the sediment after which it was transferred to a slide and covered with a coverslip.

10. To assist in the identification of cysts, a drop of iodine was placed on the other end of the slide and a drop of the sediment was added to it, mixed, and covered with a coverslip.

11. They were examined microscopically using an x10 objective and the eggs, cysts, and larvae were confirmed using the $\mathrm{x} 40$ objectives.

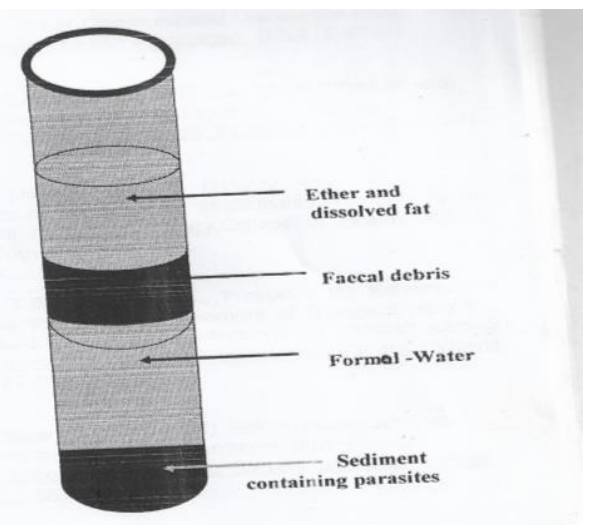

Figure 1: Formol-ether sedimentation concentration technique after centrifugation

\section{Results}

A total of 300 fecal samples were examined for intestinal parasitic infections. The results revealed that out of this, $41(13.67 \%)$ women were infected with intestinal parasites. The study also showed that out of this 41 infected women, $25(60.98 \%)$ were of the pregnant women while $16(39.02 \%)$ were the non-pregnant group.



Figure 2: Bar Chart showing the percentage prevalence of intestinal parasites among pregnant and non-pregnant women 
Table 1 shows that Ascaris lumbricoides were detected in 20 (48.78\%) of the 41 infected women, Hookworm infection in 16(39.02\%), and Entamoeba histolytica in 51(12.20\%). The table also shows that more pregnant women 25(60.98\%) than non-pregnant women $16(39.02 \%)$ were infected but the difference in prevalence was not statistically significant.

Table 1: The prevalence of intestinal parasites among pregnant and non-pregnant women

\begin{tabular}{|c|c|c|c|}
\hline Parasite & $\begin{array}{l}\text { Pregnant Women Infected } \\
(\%)\end{array}$ & $\begin{array}{l}\text { Non-Pregnant Women Infected } \\
(\%)\end{array}$ & $\begin{array}{l}\text { Total Number of } \text { Women } \\
\text { Infected }(\%)\end{array}$ \\
\hline Ascaris lumbricoides & $12(48 \%)$ & $8(50 \%)$ & $20(48.78 \%)$ \\
\hline Hookworm & $9(36 \%)$ & $7(43.75 \%)$ & $16(39.02 \%)$ \\
\hline Entamoeba histolytica & $4(16 \%)$ & $1(6.25 \%)$ & $5(12.20 \%)$ \\
\hline Total & $25(60.98 \%)$ & $16(39.02 \%)$ & $41(13.67 \%)$ \\
\hline
\end{tabular}

Table 2 shows the age-specific prevalence of infection in these pregnant and non-pregnant women. The highest prevalence of $20 \%$ in the pregnant and $25 \%$ in the non-pregnant were observed in the 27 -30years age group while the lowest $12 \%$ (Pregnant) and $6.25 \%$ (non-pregnant) were in the 19 22 years age group.

Table 2: The age-specific prevalence of intestinal parasite infection among pregnant and non-pregnant women at FMC-Owerri

\begin{tabular}{|c|c|c|c|c|c|c|}
\hline \multirow[b]{2}{*}{ Age Group } & \multirow{2}{*}{\multicolumn{2}{|c|}{$\begin{array}{l}\text { Pregnant women } \\
\text { No. Examined No. Infection (\%) }\end{array}$}} & \multicolumn{2}{|c|}{ Non-pregnant women } & \multirow{2}{*}{\multicolumn{2}{|c|}{$\begin{array}{l}\text { Total } \\
\text { No. Examined No. Infection (\%) }\end{array}$}} \\
\hline & & & No. Examined & No. Infection (\%) & & \\
\hline $19-22$ & 14 & $3(12 \%)$ & 10 & $1(6.25 \%)$ & 24 & $4(9.76 \%)$ \\
\hline $23-26$ & 25 & $4(16 \%)$ & 34 & $3(18.75 \%)$ & 59 & $7(17.07 \%)$ \\
\hline $27-30$ & 36 & $5(20 \%)$ & 35 & $4(25 \%)$ & 71 & $9(21.95 \%)$ \\
\hline $31-34$ & 35 & $5(20 \%)$ & 38 & $3(18.75 \%)$ & 70 & $8(19.51 \%)$ \\
\hline No Age & 40 & $8(32 \%)$ & 36 & $5(31.25 \%)$ & 76 & $13(31.71 \%)$ \\
\hline Total & 150 & $25(60.98 \%)$ & 150 & $16(39.02 \%)$ & 300 & $41(13.67 \%)$ \\
\hline
\end{tabular}

Table 3 shows a positive association between the prevalence of intestinal parasites and pregnant women at different stages of their pregnancy. It was observed that pregnant women within (3-4) months of pregnancy have the highest rate of infection while the least are those within (7-8) months of pregnancy with $(4 \%)$.

Table 3: Comparison of the rate of infection at different stages of pregnancy

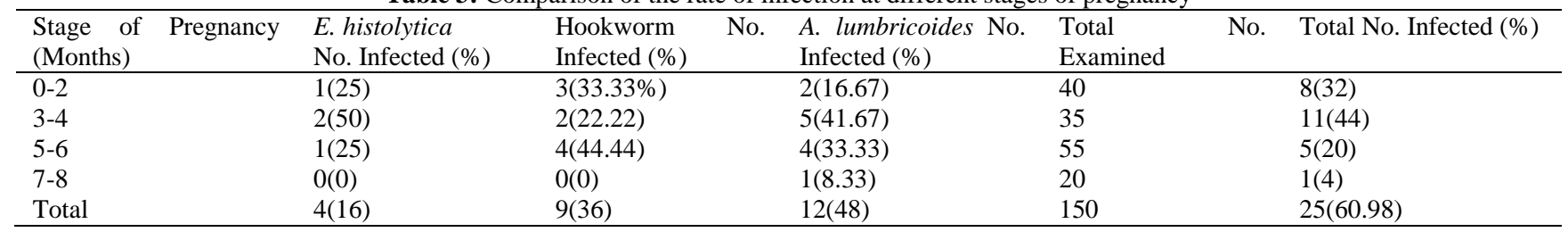

Table 4 shows the occupational percentage prevalence of intestinal parasites in pregnant and non-pregnant where it was observed that more Housewives $(38.88 \%)$ were infected than traders $(32.75 \%)$, civil servants $(12.75 \%)$ while public servants $(11.13 \%)$ had the least percentage prevalence.

Table 4: The prevalence of intestinal parasites in pregnant and non-pregnant women by occupation

\begin{tabular}{|c|c|c|c|c|c|c|c|c|c|c|}
\hline & \multicolumn{10}{|c|}{ Occupation } \\
\hline & \multicolumn{2}{|c|}{$\begin{array}{l}\text { Traders } \\
\text { No. Infected (\%) }\end{array}$} & \multicolumn{2}{|c|}{$\begin{array}{l}\text { Public servants } \\
\text { No. Infected }(\%)\end{array}$} & \multicolumn{2}{|c|}{$\begin{array}{l}\text { Housewives } \\
\text { No. Infected (\%) }\end{array}$} & \multicolumn{2}{|c|}{$\begin{array}{l}\text { Civil servants } \\
\text { No. Infected }(\%)\end{array}$} & \multicolumn{2}{|c|}{$\begin{array}{l}\text { Total } \\
\text { No. Infected (\%) }\end{array}$} \\
\hline & Pregnant & $\begin{array}{l}\text { Non- } \\
\text { pregnant }\end{array}$ & Pregnant & $\begin{array}{l}\text { Non- } \\
\text { pregnant }\end{array}$ & Pregnant & $\begin{array}{l}\text { Non- } \\
\text { pregnant }\end{array}$ & Pregnant & $\begin{array}{l}\text { Non- } \\
\text { pregnant }\end{array}$ & Pregnant & $\begin{array}{l}\text { Non- } \\
\text { pregnant }\end{array}$ \\
\hline Parasite & $40(26.67)$ & $35(23.33)$ & $55(36$. & $40(26.67)$ & $20(13.33)$ & $35(23.33)$ & $35(23.33)$ & $40(26.67)$ & $150(100)$ & $150(100)$ \\
\hline E. histolytica & $0(0)$ & $1(6.25)$ & $1(4)$ & $0(0)$ & $2(8)$ & $0(0)$ & $1(4)$ & $0(0)$ & $4(16)$ & $1(6.25)$ \\
\hline $\begin{array}{l}\text { A. } \\
\text { lumbricoides }\end{array}$ & $5(21)$ & $3(18.75)$ & $1(4)$ & $0(0)$ & $6(24)$ & $4(25)$ & $0(0)$ & $1(6.25)$ & $12(48)$ & $8(50)$ \\
\hline Hookworm & $2(8)$ & $2(12.5)$ & $2(8)$ & $1(6.25)$ & $3(12)$ & $3(12)$ & $2(8)$ & $1(6.25)$ & $9(36)$ & $7(43.75)$ \\
\hline Total & $7(28)$ & $6(37.50)$ & $4(16)$ & $1(6.25)$ & 11(34) & $7(43.75)$ & $3(12)$ & $2(13.50)$ & $25(60.98)$ & $16(39.02)$ \\
\hline
\end{tabular}

Table 5 shows the prevalence of intestinal parasites among pregnant and non-pregnant women with regards to their common sources of drinking borehole water $(32.75 \%)$ was observed among those who drank pipe-borne water.

Table 5: Percentage prevalence of intestinal parasites in pregnancy and non-pregnant women by the source of drinking water.

\begin{tabular}{|c|c|c|c|c|c|c|}
\hline 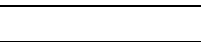 & \multicolumn{6}{|c|}{ Source of drinking water } \\
\hline & \multicolumn{2}{|c|}{$\begin{array}{l}\text { Pipe-borne } \\
\text { No. Infected }(\%)\end{array}$} & \multicolumn{2}{|c|}{$\begin{array}{l}\text { Borehole } \\
\text { No. Infected (\%) }\end{array}$} & \multicolumn{2}{|c|}{$\begin{array}{l}\text { Total } \\
\text { No. Infected }(\%)\end{array}$} \\
\hline & Pregnant & Non-pregnant & Pregnant & Non-pregnant & Pregnant & Non-pregnant \\
\hline Parasite & $50(33.33)$ & $60(40$ & $100(66.67)$ & $90(60)$ & $150(100)$ & $150(100)$ \\
\hline E. histolytica & $1(4)$ & $0(0)$ & $3(12)$ & $1(6.25)$ & $4(16)$ & $4(16)$ \\
\hline A. lumbricoides & $4(16)$ & $3(18.75)$ & $8(32)$ & $5(31.25)$ & $12(48)$ & $12(48)$ \\
\hline Hookworm & $2(8)$ & $3(18.75)$ & $7(28)$ & $4(25)$ & $9(36)$ & $12(48)$ \\
\hline Total & $7(28)$ & $6(37.50)$ & $18(72)$ & $10(62.5)$ & $25(60.98)$ & $16(39.02)$ \\
\hline
\end{tabular}


Table 6 shows that $(67.25 \%)$ of both groups of women who used pit latrines were infected with intestinal parasites, while (32.75\%) of those who used water cisterns were infected.

Table 6: The percentage prevalence of intestinal parasites in pregnant and non-pregnant women using different toilet facilities

\begin{tabular}{|c|c|c|c|c|c|c|}
\hline & \multicolumn{6}{|c|}{ Toilet facilities } \\
\hline & \multicolumn{2}{|c|}{$\begin{array}{l}\text { Pit latrine } \\
\text { No. Infected }(\%)\end{array}$} & \multicolumn{2}{|c|}{$\begin{array}{l}\text { Water cistern } \\
\text { No. Infected }(\%)\end{array}$} & \multicolumn{2}{|c|}{$\begin{array}{l}\text { Total } \\
\text { No. Infected }(\%)\end{array}$} \\
\hline & Pregnant & Non-pregnant & Pregnant & Non-pregnant & Pregnant & Non-pregnant \\
\hline Parasite & $74(49.33)$ & $85(56.67)$ & $76(50.67)$ & $65(43.33)$ & $150(100)$ & $150(100)$ \\
\hline E. histolytica & $3(12)$ & $1(6.25)$ & $1(4)$ & $0(0)$ & $4(16)$ & $4(16)$ \\
\hline A. lumbricoides & $9(36)$ & $5(31.25)$ & $3(12)$ & $3(18.75)$ & $12(48)$ & $8(50)$ \\
\hline Hookworm & $6(24)$ & $4(25)$ & $3(12)$ & $3(18.75)$ & $9(36)$ & $12(48)$ \\
\hline Total & $7(28)$ & $6(37.50)$ & $7(28)$ & $6(37.5)$ & $25(60.98)$ & $16(39.02)$ \\
\hline
\end{tabular}

\section{Discussion}

Of all the intestinal parasites found infecting pregnant and non-pregnan women in this study Ascaris lumbricoides were the commonest (48.78\%). A similar observation was made earlier by Adedeji et al. [12] and Chan [13] Ascariasis is one of the most predominant parasitic infections in southern Nigeria with considerable morbidity in pregnant women. Heavy parasites burdens may cause digestive and nutritional disturbances, blockages of the gut, abdominal pain, vomiting, restlessness, disturbed sleep, and the perforation of tissues.

The second highest intestinal parasite in the study was Hookworm, which had a prevalence of $39.02 \%$. This agrees with an earlier report by Chan [13] which showed Hookworm as the second-highest intestinal parasite with $24 \%$ prevalence [14] and, which also showed a similar trend with Hookworm infection in antenatal women. The activity of Hookworm, coupled with malnutrition, may lead to hypochromic microcytic anemia, which is a major cause of disability. Heavy, long-term infection in pregnant women may adversely affect the mental and physical development of the fetus.

The prevalence of $12.20 \%$ for Entamoeba histolytica infection was the lowest of the three intestinal parasites observed in this study. Entamoeba histolytica was the only protozoan parasite encountered. This result corroborates the finding of Cowpers et al. [15], which reported that it was the commonest protozoan parasite. The organism exists in two forms, the hardly infective cyst and the more fragile, potentially invasive trophozoite [1]. The parasite may act as a commensal or invade tissues, resulting in intestinal or extraintestinal disease. Some of the trophozoites may get into the portal circulation and are carried to the liver where they cause hepatic amoebic abscesses. They may also form abscesses [16]. Hence, the invasion of tissues by the trophozoites will adversely affect pregnancy.

The overall age-specific prevalence in the age groups revealed an increase in the infection rate with younger age. The reason could be attributed to higher exposure to the source of infection. Most of the women in the 19-22 age group were attending the ante-natal clinic for the first time, hence, lacked the knowledge of the mode of transmission of intestinal parasites. The no-age group refers to those women who did not supply information on age (Table 2). Most of the women in the no-age group likely belong to the 19-22 age-group This attitude could be attributed to young age and ignorance. The older age groups that showed low infectivity could be due to increased exposure to health programs usually organized in the ante-natal clinics. The age ranges between 27-30 recorded the highest infection rate than others which could be attributed to their way to live mainly because many of these women with a low level of health education programs ignorantly buy fruits like udara (African star apple), oranges, carrots, etc, only for them to use their wrappers or skirts to clean the fruit and start eating not minding whether the fruits are even contaminated right from the source. Moreso, many of them use toilet facilities without washing their hands with soap and water and will eventually infect themselves by using such unwashed hands to handle fruits and other food items. This high prevalence observed with this age range agrees with the studies on pregnant women and their exposure to intestinal parasites. They also attributed the high prevalence to their eating habits during pregnancy. As part of a health education program on nutrition, pregnant women should be advised to properly wash their fresh vegetables before eating.

\section{Conclusion}

This study has shown that parasitic diseases like ascariasis, hookworm infection, and amoebiasis are the major parasitic infections encountered in the study area.

Suggestions as highlighted; good personal hygiene, better health education, and highly supervised public toilet facilities together with the proper education given to food vendors, all of these put in place will greatly help in the control of these infections.

Public health authorities should be made to appreciate the significance of this study, however, stool tests should be part of the ante-natal screening test to improve the health of both the mother and the developing fetus and to reduce maternal-child mortality.

\section{References}

1. Jena, G.K., Patra, C.N. and Panda, J. (2021). Antiprotozoal Activity of Phytochemicals against Entamoeba histolytica, the Causative Agent of Amoebiasis. In Neglected Tropical Diseases and Phytochemicals in Drug Discovery (eds C. Egbuna, M. Akram and J.C. Ifemeje). https://doi.org/10.1002/9781119617143.ch5.

2. Obiamiwe, B.A. (1977). The Pattern of Parasitic Infection in Human Gu at the Specialist Hospital Benin City, Nigeria. Annals of Tropical

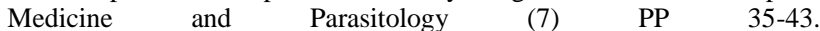
https://doi.org/10.1080/00034983.1977.11687159.

3. Akram, M., Mohiuddin, E., Adetunji, C.O., Oladosun, T.O., Ozolua, P. Olisaka, F.N., Egbuna, C., Micheal, O.S., Adetunji, J.B., Hameed, L., Awuchi, C.G., Patrick-Iwuanyanwu, K.C. and Olaniyan, O.T. (2021). Prospects of Phytochemicals for the Treatment of Helminthiasis. In Neglected Tropical Diseases and Phytochemicals in Drug Discovery (eds C. Egbuna, M. Akram and J.C. Ifemeje). https://doi.org/10.1002/9781119617143.ch7.

4. Nwosu, ABC. (1981). The Community Ecology of Soil-transmitted Helminth Infections of Humans in a Hyper endemic Area of Southern Nigeria. Annals of Tropical Medicine and Parasitology. (7) PP 35-43. https://doi.org/10.1080/00034983.1981.11687428.

5. Egbuna, C., Muhammad, K. and Ifemeje, J.C. (Eds.) (2021). Neglected Tropical Diseases and Phytochemicals. $1^{\text {st }}$ edn. John Wiley, USA. https://doi.org/10.1002/9781119617143.

6. Pugh, R. N., Burrows, S.W and Bradley, A.K. (1981). Malumfashin Endemic Endemic Disease Research xvi, Findings of a Nutritional Status. Annnals of Tropical Medical and Parasitology, 75 (3) PP 279-281. https://doi.org/10.1080/00034983.1981.11687442.

7. Steketee, R.W, Nahlen, B.L., Parise, M,E., and Menendez, C. (2001). The Burden of Malaria-endemic Areas. American Journal of Topical Medicine and Hygiene (64) (Suppl. 1-2) PP 28-35. https://doi.org/10.4269/ajtmh.2001.64.28.

8. Omer, A.S. Hamilton, P.J., Marshall, T. F. dec and Oraper, C.C. (1976). Infection with Schistosoma mansonia in the Geziel Area of the Sudan. Journal of Tropical Medicine and Hygiene (79). 115.

9. World Health Organization (1985). Mothers and Children's Care. PP 3 25.

10. Layrisse, M., Roche, M., and Baker, S.J. (1976). National Anaemias in: Nutrition in Preventive Medicine, Bento, C.H. and Bengoa, I.M (Editors) Geneva: World Health Organization, PP 13-14.

11. Cheesbrough, M. (1998). District Laboratory Practice in Tropical Countries. Pt. I. Cambridge University Press. PP 191-200.

12. Adedeji, S.O. and Ogunba, E.O. (1984). Sources of Infection with Ascaris lumbricoides in Ibadan. Paper 26, 8, Annual Conference of the Nigeria Society of Parasitology. Pp: 26-29.

13. Chan, M.S. (1994). The Evaluation of Potential Global Morbidity Attributable to Intestinal Infections. Parasitology (109) PP 373-387. https://doi.org/10.1017/S0031182000078410.

14. Effiome, O.E., Enyi-Idoh, K.H., Akpan, P.A., and Abeshi, S. (1999). Parasitic Helminth Infection on Antenatal Women at University of Calabar Teaching Hospital, Calabar. The Nigeria Journal of Parasitology. (17) P. 23.

15. Cowpers, S.G. and Woodward, S.F. (1960). Parasitic Infections Recorded At University College Hospital Ibadan, over a Three-year Period (195760). West African Medical Journal. (10) pp: 366-383.

16. Abram, S.B. (1975). Control of Communicable Diseases in Man. American Public Health Association, U.S.A. p. 413. 
Appendix I

A Copy of the Questionaire Issued

Instruction: Tick $\sqrt{ }$ in the box as appropriate.

1. NAME:

2. AGE:

$19-22 \square$

$23-26 \square$

$27-30 \square$

31-34

3. CATEGORY:

Pregnant $\square$

Non-Pregnant $\square$

4. STAGE OF PREGNANCY (PREGNANT WOMEN ONLY):

0-2 mths $\square \quad 3-4$ mnths $\square$

5-6mnths $\square \quad 7-8$ mnths

5. OCCUPATION: $\quad$ Traders $\square \quad$ Public Servants $\square \quad$ Housewives $\square$ Civil Servants $\square$

Others (specify):--

6. SOURCE OF DRINKING WATER: Pipe-borne $\square$ Bore-hole $\square \quad$ Well/Open Stream

7. TOILET FACILITIES: Pit Latrine $\square \quad$ Water Cistern $\square$

8. HOW OFTEN DO YOU PASS STOOL?: Once daily $\square \quad$ Twice daily $\square$ Thrice daily $\square \quad$ More than three times daily

9. HOW DOES THE STOOL LOOK LIKE?: Soft and formed $\square \quad$ Semi formed $\square \quad$ Loose $\square \quad$ Hard and formed $\quad$ Watery $\square \quad$ Mucoid $\square \quad$ Bloody $\square$

10. DO YOU HAVE ANY SYMPTOM(S) OF ILLNESS?: $\quad$ Fever $\square$ Headache $\square \quad$ Abdominal/Stomach $\square \quad$ Pain $\square$ Vomiting $\square \quad$ Dizziness / Weakness $\square \quad$ All of the above $\square \quad$ None of the above $\square$

Others (Please Specify): 
Appendix II

Dobell's Iodine (Constituents)

To make

Iodine crystals

Potassium Iodide

Distilled water

\section{Procedure}

The potassium iodide was weighed and transferred to a clean leak-proof brown bottle of $250 \mathrm{ml}$ capacity. The distilled water was added to the bottle, mixed well until the chemical completely dissolved. The iodine was weighed and added to the potassium iodide solution. The solution was well mixed to dissolve the iodine.

NOTE; Iodine will not dissolve in water. It is therefore important to first add the potassium iodide to the water, followed by the iodine. The bottle was labeled and marked 'Harmful'.

FOR USE: $20 \mathrm{ml}$ of the iodine solution was transferred to a small brown dropper bottle.

Physiological Saline 8.5/L(Constituents)

Sodium chloride

Distilled water

Procedure:

1.0litre

The sodium chloride was weighed and transferred to a clean leak-proof bottle. One liter of distilled water was added to the bottle, mixed until the salt was fully dissolved. The bottle was labeled and stored at room temperature.

- Thank you for publishing with us. 